\title{
The effect of climate change on depression in urban areas of western Iran
}

Hamed Abbasi ${ }^{*}$ (D)

\begin{abstract}
Objective: Human is accustomed to climatic conditions of the environment where they are born and live throughout their lifetime. The aim of this study is to examine mood swings and depression caused by sudden climate changes that have not yet given the humans a chance to adapt.

Results: Our results showed that depression could be affected by climate change and as a result, the behavior of climatic elements and trends has damaged mental health in the western regions of Iran. By investigating the trends and changes of climatic time series and their relationship with the rate of depression in urban areas of western Iran, it can be said that climate change is probably a mental health challenge for urban populations. Climate change is an important and worrying issue that makes the life difficult. Rapid climate changes in western Iran including rising air temperature, changes in precipitation, its regime, changes cloudiness and the amount of sunlight have a negative effects on health. The results showed that type of increasing or decreasing trend, as well as different climatic elements in various seasons did not have the same effect on the rate of depression in the studied areas.
\end{abstract}

Keywords: Climatic parameters, Trends, Depression, Linear regression, Variety of seasons

\section{Introduction}

One of the most important factors in controlling of human activities, is climatic factors. Climatic effects depend on several factors. The most important of them are geographical location and climatic elements of the regions. Climate change, temperature and rainfall affect various aspects of human life. One of the most important is physical and mental health. It not only affects physical health of the human beings but also the mental state of people to some extent.

Many researchers have studied the adverse effects of climate change on living environment and general health of the people in society $[6,4,5,8,9,14,16,23]$. They have shown that unhealthy quality of life and people's health depends on climatic conditions.

*Correspondence: abbasi.h@lu.ac.ir

Department of Geography, Lorestan University,

6815144316 Khorramabad, Iran
There is an evidence to show that many behavioral illnesses and mental disorders, including major depression and bipolar disorder are affected by environmental and climatic conditions $[1,2,10,11,17,18,21,22]$.

Although researchers have suggested several potential causal factors for depression, including genetic factors, low socioeconomic status, and unpleasant life events, the impact of climate change remains relatively undiscovered. A special situation in the literature of this research is that climate change causes severe events such as intensification of heat storms, floods and coastal erosion, changes in soil quality, and these natural disasters may also disrupt the underlying economic and social structures of mental health. For example, climate change may alter favorable agricultural conditions, prevent agricultural practices, and ultimately lead to job insecurity and affect the progression of depression in residents of developing countries. When there is climate change such as in mountainous place where there is lots of snow in winter, people and the soil are used to the situation and when 
there is no snow fall people in that place suffer from lack of snow and the earth suffers too. The same thing happens when in some hot areas the climate gets hotter, thus causing a lot of problems and depression. In this study, we highlighted the role of climate change in the incidence and exacerbation of mental illness (depression and bipolar).

Diseases that are studied here are acute depression and bipolar disorder. The study of climatic parameters of temperature, precipitation and current climatic conditions on human behavior in Iran has been used by many researchers [20].

This study intended to identify mood changes and depressions caused by sudden climate change in urban areas of the Zagros Mountains and introduced the parameter that has the most impact.

\section{Main text}

\section{Material and methods}

\section{Study area}

The studied areas are cities in western Iran, which are located in the Zagros Mountains. In most areas, the climate is cold and mountainous. In this regard, the statistics of synoptic stations in the region have been used. The geographical coordinates of the region are between $33^{\circ} 38^{\prime}$ to $35^{\circ} 20^{\prime} \mathrm{N}$ latitudes and between $46^{\circ} 26^{\prime}$ and $49^{\circ} 48^{\prime} \mathrm{E}$ longitudes. Figure 1 illustrates the geographical location of the studied areas.

\section{Data collection and statistical analysis}

Data were used and analyzed after some statistical tests such as run test, normal distribution and quality control. Data have a normal distribution and because of the independence of the residues, linear regression method was used. Regression method has been used in the studies such as $[3,13,19,20]$.

For assigning the relationship between climatic phenomena and mental disorders like depression, real data (minimum temperature, maximum temperature, precipitation, sunny hours, and cloudiness) were used monthly and quarterly for statistical period of 2004-2019. On the other hand, the data regarding depression were obtained based on the number of diagnoses from health centers. Due to the unavailability of statistics for depressed patients before 2004 in the target range, 15-year statistics have been used and we could not compare the statistics before 2004. Table 1 shows status of the trend of climatic parameters in the study cities.

\section{Measuring the effect of climate on depression}

To model the count time series response using various covariates, negative binomial or Poisson time series model has been used. Assuming $t$ as the unit of time, the method presented based on previous observations $\left(\alpha_{r}\right)$ as the $r$ th fourth order correlation, the conditional mean $k$ of the unit of time $(\theta)$ as the seasonal effect and the size of the estimated effect of the variables $\left(\beta_{i}\right)$. More details on the methodology, estimation and inference can be found elsewhere [7]. The Poisson time series model for the logarithm of the number of expected items $\left(\log \left(\lambda_{t}\right)\right)$ can be written as follows:

$$
\log \left(\lambda_{t}\right)=\alpha_{0}+\sum_{r=1}^{R} \alpha_{r} Y_{t-r}+\theta Y_{t-k}+\sum_{i=1}^{p} \beta_{i} X_{i}
$$

The degree of correlation was examined based on the degree of correlation between the predictors and therefore some predictions were not included in the multiple models. The significance level was considered as 0.05 .

\section{Results and discussion}

Based on the results, it was found that increasing trend of the maximum and minimum temperature in summer causes more heat, depression, and exacerbation of disease. Table 2 shows the results of analyzing the relationship between trends of climatic elements and the two diseases (major depression and bipolar disorder). In winter, the increase in the temperature in the studied areas moderates winter cold in the Zagros heights. Therefore, this increase can lead to a reduction in depression, but since in most of the studied areas, parameters such as cloudiness are increased in winter, therefore these diseases are exacerbated in these areas.

Climate parameters of cloudiness did not show a significant trend, but its trend in spring in this area was increasing, so that it had no effect on bipolar disorder but they led to acute depression. This increase was due to climate change and variability of precipitation regime in Iran [15]. In autumn, the amount of cloudiness and precipitation has decreased, which shows that in these areas, autumn has become drier than before. At the beginning of autumn it seems that it exacerbates depression, but dry air (until mid-autumn) has led to a reduction in depression in the region, which of course can be related to the beginning of autumn and the adjustment of temperatures in these areas. From semi-autumn, with the arrival of the cold season, the amount of cloudiness and precipitation increases with the arrival of western Mediterranean systems which have the greatest climatic effects in western Iran. By increasing the amount of cloudiness along with the decrease of sunny hours in winter, there is a positive effect on the rate of severe depression, bipolar disorder and the number of cases with these diseases increases as well.

Based on findings about depression in these cities, the increasing trend of spring clouds and the decreasing 


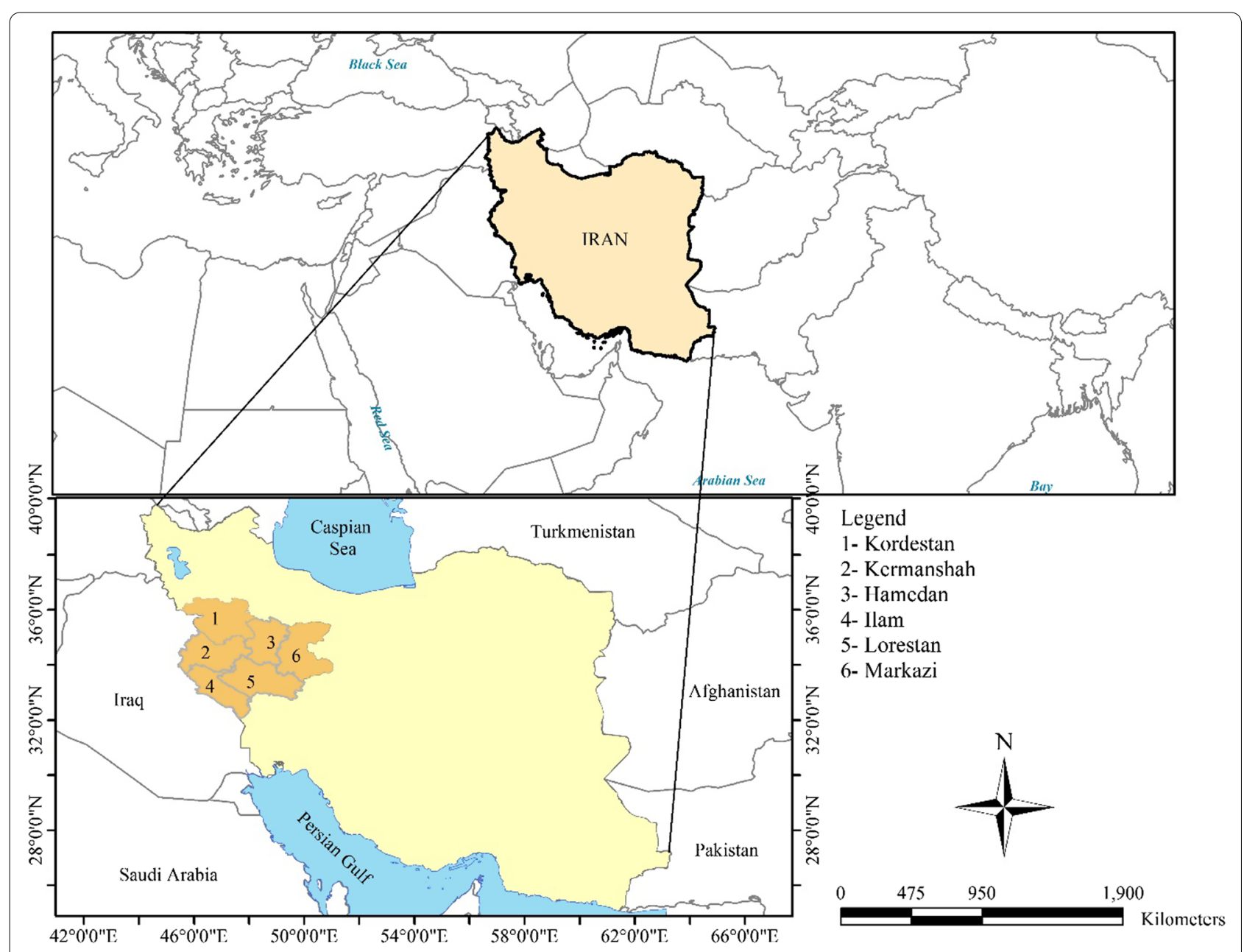

Fig. 1 Geographical location of the study area (It was drawn by H.Abbasi using free QGIS software)

Table 1 Status of the trend of climatic parameters stations of the study area

\begin{tabular}{|c|c|c|c|c|c|c|c|c|c|}
\hline Station & Height (m) & Altitude & Latitude & Type of climate & $\begin{array}{l}\text { Annual } \\
\text { sunshine } \\
\text { trend }\end{array}$ & $\begin{array}{l}\text { Annual } \\
\text { rainfall } \\
\text { trend }\end{array}$ & $\begin{array}{l}\text { Cloudiness } \\
\text { (Okta) trend }\end{array}$ & $\begin{array}{l}\max \\
\text { temperature } \\
\text { trend }\end{array}$ & $\begin{array}{l}\text { min } \\
\text { temperature } \\
\text { trend }\end{array}$ \\
\hline Arak & 1702 & $49^{\circ} 48^{\prime}$ & $34^{\circ} 1^{\prime}$ & cold semi-arid & 3 & 12 & 0.1 & 1.8 & 0.5 \\
\hline Ilam & 1360 & $46^{\circ} 26^{\prime}$ & $33^{\circ} 38^{\prime}$ & cold semi-arid & -0.1 & 6 & 0.6 & 0.9 & 0.3 \\
\hline Kermanshah & 1318 & $47^{\circ} 15^{\prime}$ & $34^{\circ} 35^{\prime}$ & Cold semi-humid & 4 & -2 & 0.4 & 1.2 & 0.25 \\
\hline Hamadan & 1741 & $48^{\circ} 32^{\prime}$ & $34^{\circ} 52^{\prime}$ & Very cold semi-arid & 14 & -17 & 0.3 & 1.6 & 0.4 \\
\hline Borojerd & 1629 & $48^{\circ} 45^{\prime}$ & $33^{\circ} 55^{\prime}$ & Cold semi-humid & 13 & 3 & 0.5 & 1.2 & 0.5 \\
\hline Khoram abad & 1155 & $48^{\circ} 17^{\prime}$ & $33^{\circ} 26^{\prime}$ & Cold semi- humid & 11 & -11 & 0.5 & 1.3 & 0.6 \\
\hline Sanndaj & 1373 & $47^{\circ} 00^{\prime}$ & $35^{\circ} 20^{\prime}$ & cold semi-arid & 10 & 13 & 0.1 & 0.8 & 0.3 \\
\hline
\end{tabular}

trend of sunny hours in winter had the greatest influence on the aggravation of depression among the climate change and trends studied.

The number of cloudy days is very low in the study area due to establishment of subtropical high-pressure summer. Therefore, frequency of depression in this season is related to the increase in the temperature and its increasing trend. In winter, with arrival of west wind systems of subtropical region in the studied areas, the number of cloudy days is increased. On the other hand, 
Table 2 Results of analyzing the relationship between trends of climatic elements on the frequency of major depression and bipolar disorder

\begin{tabular}{|c|c|c|c|c|}
\hline Response & Independent variable & Coefficient & P-value & $e^{\text {Estimate }}$ \\
\hline \multicolumn{5}{|c|}{ Major depression } \\
\hline & Max temperature & 0.230 & 0.009 & 1.259 \\
\hline & $\begin{array}{l}\text { Max temperature } \\
\text { trend }\end{array}$ & 0.442 & 0.006 & 0.843 \\
\hline & $\begin{array}{l}\text { Min temperature } \\
\text { trend }\end{array}$ & -0.508 & 0.046 & 0.602 \\
\hline & Precipitation & 0.004 & 0.018 & 0.604 \\
\hline & Mean temperature & -0.242 & 0.012 & 0.785 \\
\hline & $\begin{array}{l}\text { Mean temperature } \\
\text { trend }\end{array}$ & 0.12 & 0.007 & 1.606 \\
\hline & Seasonal effect & 0.400 & 0.005 & 1.492 \\
\hline & $\begin{array}{l}\text { Cloudiness (Okta) } \\
\text { trend }\end{array}$ & 0.642 & 0.008 & 0.943 \\
\hline & Shiny hours & 0.007 & 0.003 & 1.2 \\
\hline & $\begin{array}{l}\text { Shiny hours trend } \\
\text { change }\end{array}$ & -0.048 & 0.005 & 0.953 \\
\hline \multicolumn{5}{|l|}{ Bipolar } \\
\hline & $\begin{array}{l}\text { Max temperature } \\
\text { trend }\end{array}$ & 0.08 & 0.001 & 0.85 \\
\hline & $\begin{array}{l}\text { Min temperature } \\
\text { trend }\end{array}$ & 0.006 & 0.008 & 0.992 \\
\hline & Precipitation trend & 0.004 & 0.007 & 0.82 \\
\hline & $\begin{array}{l}\text { Cloudiness (Okta) } \\
\text { trend }\end{array}$ & 0.442 & 0.007 & 1.143 \\
\hline & Shiny hours & 0.002 & 0.028 & 1.002 \\
\hline & $\begin{array}{l}\text { Shiny hours trend } \\
\text { change }\end{array}$ & -0.24 & 0.025 & 0.986 \\
\hline
\end{tabular}

sunny hours are significantly reduced due to shortening of the day, therefore it can be said that cloudiness and reduction of sunny hours are the main climatic factors which are responsible for aggravation of depression in western region of Iran in cold season of the year. There is an important matter that the trend of climate change in depression leading to different consequences in various seasons .Obviously, sunny days in cold season of the year bring about more happiness in the studied areas, and on cloudy days with the decrease in sunlight, emotional disorders are intensified.

How climatic parameters, trends and their changes affect depression also depends on its persistence. Increasing of cloud cover is not the same in all studied areas. In semidesert and inland areas such as Arak and Hamadan despite the increase cloudy days, rainfall has decreased. In more northern regions such as Sanandaj, due to the increasing of cloudy days the amount of rainfall has also increased. The different effects of rainfall behavior and sunny hours in different regions and times can be considered. The average number of sunny hours in all areas has been increasing.
These increases together with the increase in rainfall in some areas indicates that heavy precipitation have been caused by climate change in these area.

Studying the impact of climate trends on bipolar disorder, it was found that this disease is less dependent on environmental and climatic conditions than depression. However, some seasonal trends such as decreasing trend of sunny hours and its changes in winter in some of the studied cities aggravate this disease while the trend of parameters such as cloudiness and spring temperature has little effect on its intensification.

The effect of increasing the maximum temperature of summer is also significant in exacerbating this disease. In other words, rising air temperature, intensification of summer heat in arid climate and long summer days in the studied areas cause dissatisfaction of patients with bipolar depression, therefore it seems that this disorder is more related to genetic factors. Climatic conditions and climate change have a lesser role in exacerbating the disease.

\section{Conclusions}

Climate change influences many aspects of human activities; the most important of which is the health sector. According to careful observation of the environment, it can be found that climate change leads to different reactions in the human body and mind. Climate change seems to be an important factor leading to a decrease or increase in the stress and change in the humans behavior. There is even a direct connection between these changes, trends and prevalence of some mental disorders which received less attention. Given the importance of this issue, the main objective of this research was identifying climate trends in urban areas in western Iran and investigating their effect on mental disorders, such as depression and bipolar disorder.

Studies conducted in the area showed that increasing the duration of sunshine in the cold season has a very important function in increasing people's satisfaction relative to their surroundings. Given that most people feel depressed and upset on cloudy and rainy days, it is necessary to examine the impact of climate and its changes on humans on a larger scale. This result confirms the studies of $[8,12,24]$.

In recent years, the rate of depression in urban areas of Iran has increased because of various reasons, part of which can be due to environmental conditions and climate change. Since the rainfall systems enter Iran from the west, the western regions have more rain and more cloudy days. It seems that the effect of changes in rainfall regime and the behavior of rainy seasons is more important than changes in rainfall in these areas, but in the eastern regions due to higher altitude (urban area of Hamadan and Arak) and increasing drought coefficient 
and many differences in winter and summer temperatures $\left(80^{\circ} \mathrm{C}\right)$, trends and temperature changes were more important, and one of the consequences of this increasing trend of temperature is the increase and occurrence of depression in these areas.

Considering the direct effect of rain and sunny hours on depression, it can be said that heavy rainfall, seasonal changes, the behavior of rain and sunny hours directly play an important role in the occurrence of depression and light falling of the rain in these areas with semiarid climates can have a direct effect on reducing of depression.

\section{Limitations}

One of the main limitations of this study was the lack of long-term and sufficient data on depression in Iran.

In addition to the lack of data on depression, the most important matter and limitation in conducting this study was that some depressed patients didn't go to the medical centers to be registered for their illness, so it was hidden in this study.

\section{Acknowledgements}

The author would like to appreciate the Vice-chancellor of Research and Technology of Lorestan University for their approval and support of this work

\section{Authors' contributions}

HA conceived the research topic, explored that idea, performed the statistical analysis and drafted the manuscript and approved the final manuscript.

\section{Funding}

This study was partially funded by Lorestan University.

\section{Availability of data and materials}

According to the memorandum No.14/20,008 dated 15/02/2020 (through Lorestan University); the data has been taken and analyzed. The data is available upon the request from the authors.

\section{Declarations}

Ethics approval and consent to participate

Not applicable.

\section{Consent for publication}

Not applicable.

\section{Competing interests}

The author declares no conflict of interest.

Received: 20 November 2020 Accepted: 10 April 2021

Published online: 23 April 2021

\section{References}

1. Bauer M, Glenn T, Grof P, Rasgon NL, Marsh W, Sagduyu K, et al. Relationship among latitude, climate, season and self-reported mood in bipolar disorder. J Affect Disord. 2009;116(1-2):152-7.

2. De Messias EL, Cordeiro NF, Sampaio JJC, Bartko JJ, Kirkpatrick B. Schizophrenia and season of birth in a tropical region: relationship to rainfall. Schizophr Res. 2001;48(2-3):227-34.
3. Huibers MJ, de Graaf LE, Peeters FP, Arntz A. Does the weather make us sad? Meteorological determinants of mood and depression in the general population. Psychiatry Res. 2010;180(2-3):143-6.

4. Huq M, Cheng Q, Altan O, Shoeb AZM, Hossain MA, Sarker M, Rahman M. Assessing vulnerability for inhabitants of Dhaka City considering floodhazard exposure. Geofizika. 2020;37(2):97-130.

5. Ii Islam D, Rahman A, Sarker NI, Sarker SR, Jianchao L. Factors influencing rice farmers' risk attitudes and perceptions in bangladesh amid environmental and climatic issues. Polish J Environ Stud 30(1); 2021.

6. Khan MD, Thi Vu HH, Lai QT, Ahn JW Aggravation of human diseases and climate change nexus. Int J Environ Res Public Health 219; 16(15): 2799

7. LiboschikT, Fokianos K, Fried R. tscount: an R package for analysis of count time series following generalized linear models. Dortmund: Universitätsbibliothek Dortmund; 2015.

8. Majeed $\mathrm{H}$, Lee J. The impact of climate change on youth depression and mental health. Lancet Planetary Health. 2017;1(3):e94-5.

9. Martín-Arias J, Martínez-Santos P, Andreo B. Modelling the effects of climate change and population growth in four intensively exploited Mediterranean aquifers. The Mijas range, southern Spain. J Environ Manag. 2020;262:110316.

10. McWilliams S, Kinsella A, O'Callaghan E. The effects of daily weather variables on psychosis admissions to psychiatric hospitals. Int J Biometeorol. 2013;57(4):497-508

11. Medici CR, Vestergaard CH, Hadzi-Pavlovic D, Munk-Jørgensen P, Parker G. Seasonal variations in hospital admissions for mania: examining for associations with weather variables over time. J Affect Disord. 2016;205:81-6.

12. Molin J, Mellerup E, Bolwig T, Scheike T, Dam H. The influence of climate on development of winter depression. J Affect Disord. 1996;37(2-3):151-5.

13. Ogunbode CA, Pallesen S, Böhm G, Doran R, Bhullar N, Aquino S et al. Negative emotions about climate change are related to insomnia symptoms and mental health: Cross-sectional evidence from 25 countries. Curr Psychol 2021; 1-10.

14. Pacheco SE Catastrophic effects of climate change on children's health start before birth. J Clin Investig 2020; 130(2)

15. Sabziparvar AA, Movahedi S, Asakereh H, Maryanaji Z, Masoodian SA. Geographical factors affecting variability of precipitation regime in Iran. Theoret Appl Climatol. 2015;120(1-2):367-76.

16. Sarker MNI, Yang B, LvY, Huq ME, Kamruzzaman MM. Climate change adaptation and resilience through big data. Int J Adv Comput Sci Appl. 2020;11(3):533-9.

17. Sarran C, Albers C, Sachon P, Meesters Y. Meteorological analysis of symptom data for people with seasonal affective disorder. Psychiatry Res. 2017:257:501-5.

18. Shiloh R, Shapira A, Potchter O, Hermesh H, Popper M, Weizman A. Effects of climate on admission rates of schizophrenia patients to psychiatric hospitals. Eur Psychiatry. 2005;20(1):61-4.

19. Silveira S, Kornbluh M, Withers MC, Grennan G, Ramanathan V, Mishra $J$. Chronic mental health sequelae of climate change extremes: a case study of the deadliest Californian wildfire. Int J Environ Res Public Health. 2021;18(4):1487.

20. Tapak L, Maryanaji Z, Hamidi O, Abbasi H, Najafi-Vosough R. Investigating the effect of climatic parameters on mental disorder admissions. Int J Biometeorol. 2018;62(12):2109-18.

21. Wang $S$, Zhang $X$, Xie $M$, Zhao D, Zhang $H$, Zhang Y, et al. Effect of increasing temperature on daily hospital admissions for schizophrenia in Hefei, China: a time-series analysis. Public Health. 2018;159:70-7.

22. Welham J, Davies G, Auliciems A, McGrath J. Climate, geography, and the search for candidate, nongenetic, risk factors for schizophrenia. Int J Ment Health. 2000;29(3):79-100

23. Willox AC, Stephenson E, Allen J, Bourque F, Drossos A, Elgarøy S, et al. Examining relationships between climate change and mental health in the Circumpolar North. Reg Environ Change. 2015;15(1):169-82.

24. Xu C, Wu W, Peng-Li D, Xu P, Sun D, Wan B. Intraday weather conditions can influence self-report of depressive symptoms. J Psychiatr Res. 2020;123:194-200.

\section{Publisher's Note}

Springer Nature remains neutral with regard to jurisdictional claims in published maps and institutional affiliations. 